\title{
An Experimental Study of the Value of Postsecondary Credentials in the Labor Market
}

\author{
David J. Deming, Harvard University and NBER \\ Claudia Goldin, Harvard University and NBER \\ Lawrence Katz, Harvard University and NBER \\ Noam Yuchtman, UC-Berkeley and NBER
}

\begin{abstract}
Despite growing demand, the supply of highly skilled college graduates in the U.S. has not kept pace. In contrast to sluggish growth in the public sector, enrollment in for-profit institutions has grown rapidly over the last fifteen years. Yet little is known about the labor market return to a for-profit education. Do employers value for-profit credentials, and do they value credentials from some institutions more than others? We address these questions using a large-scale resume audit field experiment. We construct fictitious resumes, randomly vary the institution from which the job applicant received a degree or certificate, and apply to job vacancies that are posted on a large, national job search website. While our primary research question concerns employers' valuations of a for-profit versus public credential, we also test the impact of having any credential for job vacancies that do not require it. Additionally, our planned sample size allows us to examine heterogeneity by occupation, degree, and labor market. In this pre-analysis plan, we describe the structure of the experiment, and we present early results from a pilot version of our study. The full version of the study went into the field on Monday, March $31^{\text {st }}$ and will conclude by the end of June 2014.
\end{abstract}

Acknowledgements: We wish to thank Noam RA \#1, Noam RA \#2, Noam RA \#3, Barbara Halla, Rugsit Kanan, Megan Prasad, Adela Soliz, and Jonathan Whittinghill for superb research assistance. We give special thanks to Amira Abulafi, who managed our research team and played an important role in the development of the study. We also wish to thank seminar participants at Princeton University for helpful feedback. This research is supported in part by the Institute of Education Sciences, U.S. Department of Education, through Grant R305C110011 to Teachers College, Columbia University. This study has been approved by the Harvard IRB (IRB13-1856) and was submitted to the American Economic Association Randomized Controlled Trial Registry on March 30 ${ }^{\text {th }}, 2014$. 


\section{Introduction}

The demand for U.S. college-educated labor has grown rapidly in recent decades, yet the supply has not kept pace (Goldin and Katz 2008, Acemoglu and Autor 2010). America, once the world leader in postsecondary education, has fallen to $12^{\text {th }}$ among OECD nations in terms of the share of young adults (those 30 to 34 years old) attaining a bachelor's degree and to $13^{\text {th }}$ for any post-secondary degree (OECD 2013, Table A1.3a). In a 2009 address, President Barack Obama asked every American to commit to at least one year of higher education or career training, with the goal that by 2020 America will "once again have the highest proportion of college graduates in the world."

Despite growing demand for their graduates, inflation-adjusted public funding of postsecondary education has been stagnant since the mid-1990s and has declined substantially in the last decade (College Board, 2014). Decreases in public funding have led to higher net tuition for college students. From 2000-2001 to 2010-2011, the share of public institutional revenues from federal and state sources fell from 79 to 66 percent in two-year institutions and from 70 to 54 percent in four-year institutions, with net tuition and fees making up the difference (College Board, 2014). Time to degree has lengthened and completion rates are declining as students receive fewer resources per capita and face difficulty enrolling in courses that are necessary for graduation (Bound, Lovenheim and Turner 2012; Pearson Foundation 2011 ).

In contrast to sluggish growth in the public sector, enrollment in for-profit postsecondary institutions grew rapidly from 2000 to 2010 until levelling off over the past few years. The for-profit postsecondary education sector accounted for about 60 percent of total enrollment growth in higher education between 2000 and 2010 peaking at 11.2 percent of total fall enrollments in Title IV-eligible institutions in 2010(Deming, Goldin and Katz 2012). For-profit institutions enroll a disproportionately high share of disadvantaged and minority students and those ill-prepared for college. Yet little is known about the labor market returns to a postsecondary credential from a for-profit institution. On the one hand, forprofit colleges train non-traditional learners for jobs in fast-growing areas and can quickly adjust to the changing needs of employers. On the other hand, they derive most of their revenue from taxpayerfunded student financial aid, and the loan default rates of students in for-profit institutions vastly exceed those of their counterparts in the public sector.

Few existing studies have estimated the labor market returns to a for-profit college education (e.g. Cellini and Chaudhary 2012; Deming, Goldin and Katz 2012, 2013; Lang and Weinstein 2013). None of these studies uses a randomized or strong quasi-experimental design. Moreover, all previous studies draw on the relatively small number of students attending for-profit institutions in nationally representative, publicly available data sources. As a consequence, they are unable to examine heterogeneity across employment sectors, institution types and labor markets.

How does the labor market value postsecondary education credentials from for-profit and public institutions respectively? We address the question with a large-scale randomized resume audit study. Our plan is to send fictitious resumes to actual help-wanted ads in six to nine large labor markets and across four major occupation groups (business, admin/clerical, information technology and allied health 
occupations). Our goal is to ask whether employers place a different value (as proxied by the probability that a job application receives a callback) on observably identical job applicants who have postsecondary credentials from public or for-profit institutions. Importantly, we are also interested in the returns to a postsecondary credential relative to no credential, or relative to additional work experience. If community colleges are overcrowded or unavailable, then an important comparison will be that between a for-profit degree and no degree.

We follow in an established tradition of resume audit experiments in economics, including studies of discrimination by race (Bertrand and Mullainathan 2004), gender (Riach and Rich 1987), age (Lahey 2008), immigrant status (Oreopoulos 2011) and duration dependence (Kroft, Lange and Notowidigdo 2013). We are interested in whether employers statistically discriminate based on receipt of a degree or certificate from different types of postsecondary institutions. Importantly, any differential callback rate by sector or institution could be due broadly to three factors: 1) the employer perceives that one type of program improves human capital acquisition more than another; 2 ) the employer perceives that one type of program signals greater innate productivity than another; and 3) the employer has no belief about differences in productivity, yet has an idiosyncratic taste for graduates of one type of institution over another. This last explanation could arise because of network effects, or because the employer has never heard of one of the schools (or likes or dislikes the school's "brand").

Because of the randomized design, this study will have high internal validity. Thus, the key task is to think carefully about external validity. To what extent does our study approximate the actual job search process of newly minted graduates at each type of institution? Do our resumes look like the resumes of real job-seekers with these credentials?

We took several steps to maximize external validity. First, we chose a large, national job search website that posts thousands of new jobs every day across the entire United States. This website includes highskilled, high-quality jobs that are posted by large employers. We chose large occupation groups and labor markets with significant representation across postsecondary education sectors, so that the actual employers are likely to get applicants with degrees from both sectors in the pool of job seekers. We chose postsecondary institutions with significant representation in each labor market. We culled information on education and employment histories from actual resumes in each labor market and occupation group combination, using a large online resume bank. We then constructed our fictitious resumes to mimic new graduates and job seekers in these markets. Our fictitious resumes will be sent out when new graduates will be seeking employment (late March through the end of June).

This pre-analysis plan proceeds in four parts. Section 2 describes the experimental setting, including the occupations, labor markets and job vacancies that we study. Section 3 describes the details of resume construction and the mechanics of how we will apply to job vacancies. Section 4 discusses our data collection and analysis plan, including expected sample size and statistical power, the specific estimating equations, and a discussion of planned subgroup analyses. Section 5 concludes with some preliminary evidence from a pilot study that we have run for the past two months. 


\section{Experimental Setting}

\subsection{Occupation Groups and Degrees}

Table 1 lists the occupation groups and degrees that we study - AAs and BAs in business, administration, and information technology, and certificates and diplomas in allied health. We group degrees into occupational categories using the Classification of Instructional Programs (CIP) coding scheme, which is also used by the U.S. Department of Education and Department of Labor. Business and administration is, by a large margin, the most common degree category awarded by both public and for-profit institutions. Allied health and information technology are the second and third largest groups, and together contain 13 of the 20 fastest growing occupations projected by the Bureau of Labor Statistics from 2012 to $2022 .{ }^{1}$

Columns 1 and 2 of Table 1 show the share of awards (degrees or certificate) to each occupation group conferred by public and for-profit institutions within each degree level, based on 2012 data from the Integrated Postsecondary Education Database (IPEDS). Among public sector institutions, 12 percent of associate's degrees and 16 percent of bachelor's degrees were awarded in the business, administrative and information technology fields. Among for-profit institutions, the comparable figures are 25 and 45 percent. Among all certificates/diplomas awarded by public institutions, 14 percent were in allied health, and among for-profits the figure is 38 percent. $^{2}$ The for-profit institutions award a larger fraction of their degrees and certificates in applied field and especially in the health fields.

Column 3 presents the share of all credentials in each category that were awarded by for-profit institutions in 2012. For-profits are well represented in each degree or certificate group, ranging from 10 percent of all BAs in Accounting or Finance to 86 percent of all Diplomas in Medical Assisting. In 2012, for-profit institutions were responsible for about 43 percent of less-than-2-year certificates/diplomas and 20 percent of all AAs across all occupation groups. For-profits award only 8 percent of all BAs, but the $B A$ is the fastest growing degree category for the for-profit sector (with the for-profit accounting for only about 1 percent of BAs in 2000 and 2.5 percent in 2005). For-profits account for a larger share of all business, administration and IT degrees - about 30 percent of all AAs and 15 percent of all BAs. Moreover, the BAs are mostly awarded by the large, publicly-traded and primarily online institutions that have been the subject of recent regulatory scrutiny.

\subsection{Job Vacancies}

Our source of job vacancies is a large online job search website that posts thousands of new job vacancies each day, across the entire United States. Our IRB prohibits us from revealing the exact name of the site. The website posted about 32,000 new vacancies per day during March, and about 60,000

\footnotetext{
${ }^{1}$ http://www.bls.gov/ooh/fastest-growing.htm

${ }^{2}$ While some institutions also offer AAs in allied health fields such as medical assisting, this is both inconsistent across institutions and much more common in the for-profit sector. Moreover, most institutions that offer the AA also offer a shorter diploma in the same category. For this reason, we focus on diplomas and certificates rather than AAs in the allied health category.
} 
jobs over successive three-day periods, for an estimated total of 600,000 to 960,000 jobs per month. ${ }^{3}$ According to the Job Openings and Labor Force Turnover Survey (JOLTS), there were about 3.8 million total nonfarm job openings in the U.S. in March 2013. If the small rise in openings from January 2013 to 2014 keeps pace through March, there will be about 4 million job openings in March 2014. Thus we estimate that the job search website in our study captures between 15 and 24 percent of all U.S. job openings at this time.

We search for eligible jobs in each category using a combination of keyword searches and default occupational classifications, which are defined by the website and based on the Occupational Information Network classification scheme (O*NET) developed by the U.S. Department of Labor. Across all occupations and labor markets, we focus on jobs that require four or fewer years of work experience, including entry-level positions. Similarly, and as we describe in more detail later, most of our resumes will be constructed to have four years of work experience (which may include externships and part-time work).

The focus on entry-level and early career positions has two advantages for our study. First, early career is when the postsecondary institution is arguably most salient to potential employers. All of our resumes will list the degree or certificate as awarded (or expected) between April and June 2014, maximizing the salience of the credential to employers. Second, four years of post-high school work experience is roughly consistent with the modal age (about 23) for students who obtain degrees from for-profits and community colleges (Deming, Goldin and Katz 2012).

For Business, Administrative and IT occupations, we apply to two groups of jobs. The first category is jobs that do not require a degree, or jobs that only require an AA. We have concluded based on the results of our pilot study and informal inspection that few vacancies in the Business, Administrative and IT occupations require an applicant to have an AA, although some say "AA preferred". Importantly, the vacancies that require an $A A$ appear qualitatively similar to those that do not require a degree, while the vacancies that require a BA look quite different. The second category of Business, Administrative, and IT jobs to which we apply are those that require a BA degree, but only when the vacancy also requires no more than two years of work experience.

Licensed Practical Nursing and Pharmacy Technician jobs universally require a diploma from an accredited institution and a valid license. All of our resumes in these categories will have these credentials. Medical Assistant vacancies (both administrative and clinical) are somewhat more heterogeneous, and do not always require a diploma or specific license. As we describe later, our application process is somewhat different for vacancies that do and do not require a credential.

Table 2 lists the categories of occupations in our study, sample job titles, the associated postsecondary credential, and the average share of all full-time job vacancies that fall into each occupation category

\footnotetext{
${ }^{3}$ Some of the jobs posted over successive 24 hour periods may be duplicate listings. On the other hand, it is also common for employers to post job vacancies for only a day or two before pulling them down. Thus, we use the 72 and 24 hour windows as estimates of the lower and upper bounds (respectively) of the number of new job vacancies per month posted on this job website.
} 
based on successive searches of the job website from mid to late March. ${ }^{4}$ Note that some vacancies will fall into multiple categories (e.g., customer service and administrative) and so the total shares across categories could sum to more than 1 . Still, Table 2 shows that the job categories in our study represent a healthy share of the overall labor market.

\subsection{Labor Markets}

We conduct our study in nine of the largest metropolitan labor markets in the United States. We group regions by the combined statistical area (CSA) definition developed by the U.S. Census Bureau and used in IPEDS. ${ }^{5}$ Table 3 lists the CSAs in our study, along with the share of all U.S. postsecondary credentials given out by institutions in each CSA. ${ }^{6}$ Overall, the labor markets in our study represent about 30 percent of all postsecondary awards, and about 26 percent of all full-time job vacancies.

It is necessary for us to study large labor markets to ensure that there is sufficient overlap of degrees awarded and occupations across public and for-profit institutions. In many smaller labor markets, a large majority of postsecondary credentials are given out by one or two institutions, often within a single sector. Moreover, there are returns to scale in applying to similar types of jobs within the same labor market.

\section{Resume Construction and Job Applications}

\subsection{Postsecondary Institutions}

In principle, we would like our resumes to be representative of the postsecondary credentials awarded within each labor market, occupation and sector. For example, if 20 percent of all diplomas in medical assisting among for-profit institutions in Chicago are awarded by Everest College, then 20 percent of our resumes with for-profit institutions would list a diploma from Everest College. Perfect representation is logistically difficult, however, because of the large number of institutions that award only a few credentials and the need to create many resume templates for low probability events.

In practice, we pursue a strategy that weights resumes in rough proportion to the share of awards given out in 2012 (the most recent available year) by each program in each metropolitan area, but with only the largest programs in each labor market represented. This representation also includes online institutions, which award credentials to students all across the country. The IPEDS data indicate that in 2012, between 50 and 60 percent of business and IT degrees in the for-profit sector were awarded by

\footnotetext{
${ }^{4}$ We compute this share by 1 ) searching for all full-time job vacancies in the last 24 hours; 2 ) search for full-time job vacancies within a particular occupation category (based on keyword searches); 3 ) dividing \#2 by \#1. We do this for three consecutive days and take the average to arrive at the shares in Table 2.

${ }^{5}$ See this map for a visual display of CSA definitions http://www2.census.gov/geo/maps/metroarea/us_wall/Dec_2009/csa_us_1209_large.gif

${ }^{6}$ This includes institutions that are physically housed in a particular CSA but offer many or most degrees online, such as the University of Phoenix. IPEDS data cannot track the physical location of degree recipients from online universities, at least not at the CSA level. Also, we use the Core-Based Statistical Area (CBSA) definition (developed by the Office of Management and Budget (OMB)) for the Phoenix-Mesa-Scottsdale area, since Phoenix is not grouped into any CSA and we wanted to include it in our study.
} 
institutions that are fully online. Therefore, we adopted the convention that at least half of all for-profit degrees (and, in cases where no local for-profit awarded a significant number of degrees, 100 percent) in the business and IT fields were from online institutions such University of Phoenix or DeVry University, with the other half coming from local brick-and-mortar institutions in rough proportion with their size. However, we used local brick-and-mortar public institutions (weighted by size) in all cases. ${ }^{7}$ We restrict our public four-year degrees to come from the least selective public institutions in the CSA as measured by the 2012 Barron's rankings. ${ }^{8}$

Unlike business and IT, only a very small share of diplomas and certificates in allied health are awarded by online institutions. Many administrative and nearly all clinical health programs require the completion of an externship. Therefore, all of our resumes for health jobs will list local brick-and-mortar institutions, again in rough proportion with their total share of certificates or diplomas in each category.

\subsection{Work Experience}

We populate our resumes with actual work histories from a free online resume bank. It is a large website with a publicly-available bank containing more than 3.5 million resumes for the nine local labor markets that we study. We search the database for suitable matches for each occupation-degree-labor market combination (ex: a diploma in medical assisting from Everest College in the Chicago CSA). We then pull the actual work experience profiles for qualified resumes from the four years prior to graduation from the program. Whenever possible, we use complete pre-schooling work histories without modification. However, in some cases we omit older jobs or change names to avoid singling out identifiable small employers (such as the office of a particular doctor).

This process results in a small number of work history templates over which we will randomize. We populate each resume pool with an equal proportion of work histories from resumes of individuals that attended public and for-profit institutions. In general, we seek to find the "common support" across these resumes to approximate the marginal attendees across sectors. For example, while it might be the case that the average work histories look better for community college (or for-profit) attendees, our research design will instead isolate the impact of the postsecondary institution for the type of work experience profile that fits well at both types of institutions.

\subsection{Skills, Race, Gender and Other Characteristics}

Some additional features of the resumes are worth mentioning. First, we adopt a standard template for all resumes that lists (in order) name, contact information, degree, work history, and skills and additional information. Job seekers who post their resumes in this resume bank are required to fill out information about themselves in a series of fields, which then spits out the standard template. We

\footnotetext{
${ }^{7}$ While many community colleges offer courses online, such online courses are typically part of a hybrid program with face-to-face elements, rather than a fully online program. Moreover, in states such as California, Texas and Florida, students who live in the community college district receive preferential tuition pricing and course access. ${ }^{8}$ Specifically, we choose only from institutions that rate as "Competitive" or "Less Competitive", so that our public institutions are drawn from the bottom 50 percent (and when possible, the bottom 20 percent) of the selectivity distribution.
} 
follow this template with the one exception that we list the degree right below contact information (the default is to list the degree after work experience, which is more common among experienced job seekers).

One important decision is whether to include the high school degree. Although it is not common for resumes with a postsecondary degree to list the high school from which they graduated, it is also not particularly unusual. Moreover, resumes that do not have a postsecondary credential commonly list a high school diploma and the school attended, perhaps because many jobs require applicants to have a high school degree or GED. Therefore, we elect to include a high school and graduation date on every resume. Listing the date of graduation also bounds past work history and ensures that resumes are not hiding older work history gaps, a factor that is known to be important to employers (Kroft, Notowidigido and Lange 2013). Using the Common Core of Data (CCD), we sort all regular (non-charter, nonspecialized) high schools in a CSA by racial composition and select the 4 schools that represent the median student of each race. We then randomly assign each of these high schools to our resumes.

We follow the convention of past resume audit studies and signal race/ethnicity and gender through first and last names. We choose common names for each race/ethnicity and gender, subject to the logistical constraint that the names conform to a common set of first and last initials. We do this so that we can re-use email addresses across names (e.g., tj251@gmail.com could be Timothy Johnson, Tyrone Johnson, or Tomas Jimenez). As described in more detail below, we stratify job applications by race and gender to try to detect a differential impact by race and gender.

In addition to the email address, each resume will list a local phone number that we have created to monitor callbacks. Under no circumstances will these calls be answered. We use a standard voicemail recording that prompts callers to leave a message. We will record all callbacks as data, although our IRB requires that we destroy the phone records immediately after collecting the relevant information for our study.

\subsection{Applying to Job Vacancies using Randomly Generated Resumes}

Members of our research team are tasked with particular labor market and occupation combinations (e.g., IT jobs in New York, Chicago and Miami). Each day, they conduct the appropriate search on the job website and arrive at a set of eligible job openings that have been posted in the last 24 hours. In addition to the work experience requirements described above, we limit eligibility in two additional ways. First, while the large majority of vacancies allow users to apply and upload their resumes directly through the website, we exclude vacancies that are simply links to a secondary website or that are posted by staffing companies. We do this for practical reasons, but also because many of these postings are attempting to add resumes to a bank to distribute to other employers, rather than filling a vacancy directly. Second, we exclude all vacancies that explicitly set pay based on sales commissions due to concerns that these jobs are not of sufficiently high quality to be considered "good" outcomes for graduates of postsecondary programs.

As described earlier, we create a set of resume templates for each occupation-degree required-labor treatment cell. Using the Resume Randomizer program developed by Joanna Lahey, we randomly assign 
the combination of name, postsecondary institution, work history and additional skills for the appropriate cell, and we directly upload (in random order) four randomly created resumes to each job vacancy. We have been able to verify that employers do not observe the login information of the person who uploads the resumes, so there is no way to trace the fact that multiple resumes were uploaded from the same login or IP address. We randomly assign race and gender (implied by name) between job vacancies rather than within them. We take this approach to maximize power for our main treatment of interest (postsecondary sector), while preserving our ability to detect differential impacts by demographic group.

After our research assistants upload resumes to the job vacancy, they will copy all available information about the job (firm name, job title, requirements, salary if available, and the text of the job description) into a spreadsheet and upload to it to our project Dropbox. Research assistants are instructed to keep track of job applications across days and job categories to ensure that we do not apply to the same vacancy more than once or to the same firm within a 2-week period. The research assistants will not be responsible for recording callbacks.

\subsection{Treatments}

Table 4 contains a summary of the structure of the experiment. For Business, Administrative and IT jobs that require an AA or no credential, we send two resumes that do not have a degree, but we vary the length of the work history between 4 and 6 years by adding 2 years to the most recent job. We include a resume with two additional years of experience to simulate the thought experiment of a potential student who decided to continue working at his or her current job, rather than attending school. The third and fourth resumes in this grouping have AAs from public and for-profit institutions respectively, plus four years of work experience that is concurrent with the degree. We use concurrent work histories because such patterns are common among students in both sectors.

For jobs that require a BA, all of our resumes will have the degree, but we systematically vary the postsecondary sector and work experience. The modal work history pattern for students who attend less-selective four-year public institutions is intermittent employment, including some full-time work, but also part-time jobs and internships. On the other hand, the modal pattern is full-time work for students who attend BA programs in for-profit institutions. Therefore, we create a $2 \times 2$ design that matches these work history patterns with degrees from each sector. When possible, we pull actual work histories from the "off-diagonal" groups (i.e., students who attend 4-year publics but work full-time, forprofit students who work part-time).

For allied health jobs that require a credential, we send two resumes that have a diploma or certificate from a public institution and two that have the same credential but from a for-profit institution. All four resumes include three years of non-medical or "medical uncertified" work experience as well as an externship which is completed concurrent with the program (which is one year in length). Most accredited programs in allied health require the completion of an externship of specified length (e.g. 75 hours, 160 hours) in a clinical setting. We draw these externships from actual resumes in the online 
resume bank. The "medical uncertified" category of work experience includes medical office work experience, and in some cases unlicensed care jobs such as home health aides.

For allied health jobs that do not require a credential, we send one resume each of the public and forprofit types described above, with an externship plus three years of non-medical or "medical uncertified" experience. The third and fourth resumes do not have a diploma or certificate, but they vary in their work history profiles. The third resume is identical to the first and second except that it does not have a postsecondary credential. The fourth resume also has no credential, but contains one year of "relevant" work experience. This "relevant" work experience is constructed by lengthening the spells of the externships on the resumes that do include a credential, and altering the description when necessary so that it appears to be full-time work. This will allow us to test the extent to which the impact of having a diploma is mediated through placement in a work externship.

Not all students who begin at public and for-profit institutions eventually complete a degree - in fact, certificate completion rates in both sectors hover around 50 percent, and associate's degree completion is around 30 percent in for-profits and less than 20 percent in community colleges (Deming, Goldin and Katz 2012). Thus, one possibility is to include treatments where we send resumes with some college credits completed but no degree. We do not pursue this approach, for two reasons. First, our examination of actual resumes in the online resume bank shows that reporting of years of education if often unclear or even deceptive. ${ }^{9}$ The concern is that this lack of clarity could lead to a higher probability of callback but a lower conversion rate of callbacks to hires, as employers learn the truth about prospective job applicants' education history. Second, Deming, Goldin and Katz (2012) show that after statistical adjustment for pre-enrollment covariates such as income and family background, completion rates across sectors are very similar. The findings suggest that the marginal student may be equally likely to complete at each type of institution.

\section{Data Collection and Analysis Plan}

\subsection{Data Collection}

Table 5 presents some sample power calculations. The well-crafted recent resume audit study by Kroft, Lange and Notowidigdo (2013) achieved a callback rate of around 5 percent. The baseline callback rate in our pilot was a bit higher at around 7 percent. At a 5 percent overall callback rate, we estimate that we need to apply to about 3,728 (2,936) jobs to detect a 1 percentage point difference in callback rates between resumes from for-profit and public institutions at a 5 percent (10 percent) significance level with 80 percent power. For a baseline callback rate of 7 percent, the required number of jobs is a bit higher at 4,024 for a 10 percent significance level. If we widen the minimum detectable effect size to 1.5 percentage points, our sample size requirements drop relatively steeply $(2,567$ and 1,656 jobs at a 5 percent significance level with baseline callback rates of 7 and 5 percent respectively).

\footnotetext{
${ }^{9}$ For example, it was common to see education listed as "University of Massachusetts-Boston, 2011-2014, Major: Marketing" but without an actual degree listed.
} 
Therefore, we set a goal of applying to 4,000 jobs (16,000 resumes) to detect an overall impact of 1 percentage point. One of the major goals of the study is to examine heterogeneity by degree and occupation categories. We expect that we will be able to detect effect sizes of 1.5 percentage points or greater for key subgroups such as business vs. health or certificate/diploma vs. AA vs. BA.

The start date of the experiment is Monday, March 31. We estimate that a research assistant can apply to about 3 to 4 jobs per hour based on our pilot study. We have assembled a team of 9 research assistants, each working 2 to 3 hours every workday (so 10-15 hours total). By this rough calculation, we will be able to apply to about $3.5 * 12.5 * 9=394$ jobs (sending out 1,575 resumes) per week. At this pace, our study will conclude between the end of May and the middle of June 2014. Because our RAs will be uploading data on their job applications to our project folder at the end of each day, we can track the progress of our study in real time and make sure that we are keeping pace. Although we plan on finishing our study in early June, we may extend some particular treatments to gain power - however, we will not alter the basic structure of the experiment.

There are two main advantages of conducting our study in April, May and June. First, data from JOLTS shows that these are three of the highest volume months in terms of job openings. Second, since our job applicants will be the recipients of newly awarded degrees, the name of the postsecondary institution will be highly salient.

Importantly, RAs will not be responsible for recording callbacks. We will record and code callback data separately, for two reasons. First, our IRB requires that we handle these data securely, since they record individual firms' behaviors. Second, by decoupling applications and callbacks, we can enlist members of our research team to code callbacks without knowing which postsecondary institutions were listed on individual resumes.

We plan to code callback data in a variety of ways. The most restrictive version creates an indicator variable that is equal to one if the caller specifically requests an interview. In our pilot study, a bit less than 15 percent of all calls were requests for additional information rather than explicit interview requests, so we can code that as a separate outcome or combine them. Finally, our plan is to link phone numbers to treatment cells, so that a call and hang-up (which constituted around 10 percent of all calls in our pilot study) can still be recorded as data.

\subsection{Data Analysis}

Our basic estimating equation will take the following form:

$$
Y_{i c g}=\beta_{1} F P_{i c g}+\beta_{2} P U B_{i c g}+\delta X_{i c g}+\gamma_{c}+\theta_{g}+\varepsilon_{i c g}
$$

In this model, $\mathrm{Y}$ is an indicator variable that is equal to one if individual resume $i$ in core statistical area $c$ and occupation-by-degree group $g$ receives a callback from an employer. $X_{i c g}$ is a vector of covariates such as race, gender, work experience and skills, which is included in the main estimating equation only for balance. $\gamma_{c}$ and $\theta_{g}$ are fixed effects for labor markets and occupation-by-degree groups respectively. 
This simple setup allows us to test our key hypotheses - FP vs. public, FP vs. nothing, public vs. nothing. For treatment cells where all resumes have a degree or certificate, $\beta_{2} P U B_{i c g}$ would drop out and become the left-out category, leaving $\beta_{1}$ as the estimate of having a for-profit credential relative to a public credential. To test for variation in impacts when a degree is required, we can augment equation (1) with interactions between sector and degree required:

$Y_{i c g}=\beta_{1} F P_{i c g}+\beta_{2} P U B_{i c g}+\delta_{1} F P_{i c g} * D e g R e q_{i c g}+\delta_{2} P U B_{i c g} * D e g R e q_{i c g}+\varphi X_{i c g}+\gamma_{c}+\theta_{g}+\varepsilon_{i c g}$

Where $\delta_{1}$ and $\delta_{2}$ give the differential effect of postsecondary education sector for job vacancies that require a degree. We will estimate equations (1) and (2) using a linear probability model. We will check the robustness of our findings to a logit specification as well (especially if the dependent variable is sufficiently close to zero).

\subsection{Subgroup Analyses}

We can augment equation (1) with a series of interaction terms that test for variation in the impacts of postsecondary education sector by the elements of $X_{i c g}$ or by the labor market and occupation-bydegree group fixed effects. The general form is:

$$
Y_{i c g}=\beta_{1} F P_{i c g}+\beta_{2} P U B_{i c g}+\delta_{1} F P_{i c g} * X_{i c g}+\delta_{2} P U B_{i c g} * X_{i c g}+\varphi X_{i c g}+\gamma_{c}+\theta_{g}+\varepsilon_{i c g}
$$

Where $\delta_{1}$ and $\delta_{2}$ give the differential effect of postsecondary education sector by a key covariate in

$X_{i c g}$ such as race or gender. We can also test for differential effects by labor market or degree category by estimating fully-interacted models and conducting an F-test for the hypothesis that the separate effects by labor market (for example) are jointly significant.

The following is a list of subgroup analyses that interest us ex ante: race, gender, local labor market, institution characteristics (such as size, public ownership, selectivity, and the cohort loan default rate provided by the U.S. Department of Education), occupation (business, health etc.) and degree level (AA or BA). One hypothesis that we are particularly interested in testing is that employers may differentially value a credential when it is associated with a licensing requirement or (in general) a more measurable and verifiable skill set.

Finally, Neumark (2012) shows how variation in application characteristics that are correlated with unobserved predictors of productivity can affect the inferences that we draw from resume audit studies. Along these lines, we plan to use ex post variation in the quality of work experience profiles (as measured by random differences in callback rates) to test for differential callback rates by resume quality. In doing so, we hope to learn something about the mechanisms for any differential callback rate we observe. For example, if employers are less likely to call back resumes with a for-profit credential, but yet that difference narrows for higher-quality resumes, one might infer that employers are statistically discriminating based on unobserved characteristics of for-profit degree holders. 


\section{Pilot Study}

In January and February of 2014 we conducted a small pilot study of a single occupation group in a single labor market - administrative and clerical positions in the Chicago CSA. We attempted to make all fictitious names both female and "race neutral", in the sense that they were not obviously associated with a particular ethnic group. Our research design for the pilot study called for us to send 3 resumes to job vacancies that did not require a degree, and 2 resumes to jobs that required an AA or higher. Overall, about two-thirds of jobs were in the first category. All of our resumes with postsecondary credentials were randomly assigned to one of two institutions - a large online for-profit, or a single large and local community college.

We sent 278 resumes to 104 jobs. The baseline callback rate was 7.2 percent. For the pilot study, we code a "callback" as a voicemail message left by a prospective employer that either asks for an interview or requests additional information. More than 80 percent of messages were requests for an interview, and there was no meaningful difference across postsecondary education sectors. In the full version of the study, we will examine the sensitivity of our results to the decision to code all callbacks as positive responses, relative to only counting interview requests.

Without statistical adjustment, the callback rate was 9.5 percent for resumes with a degree from a community college, 7.5 percent for for-profit degrees, and 5.5 percent for resumes with no degree listed. Table 6 presents regression-adjusted estimates, using a specification like equation (1). Column 1 restricts the sample to job vacancies that do not require a degree, and so "no degree" is the left-out category. We find that resumes with an Associate's degree from a community college are 3 percentage points more likely to receive a callback than resumes with a for-profit AA or no degree, although unsurprisingly the standard errors are too large to say anything conclusive. Column 2 adds controls for each individual (randomly assigned) work history. Consistent with random assignment, this has no impact on the point estimates.

Columns 3 and 4 add the resumes that were sent to vacancies that required a degree. We estimate a simplified version of equation (2), which allows the impact of a for-profit or public credential to vary with the "degree required" provision. Column 3, which includes no other controls, shows that the callback rate is exactly the same across sectors for jobs where a degree is required (adding the main effects and interaction terms together for both sectors yields the same total -5.1 percentage points). Column 4 adds work history fixed effects. After controlling for previous employment history, resumes with a community college degree are about 5.3 percentage points more likely to receive a callback than resumes with a for-profit degree among applications to jobs that require a degree. In all cases, however, standard errors are too large to conclude that any differences are statistically significant. 


\section{References}

Acemoglu, D. and D. Autor (2011). Skills, tasks and technologies: Implications for employment and earnings. Handbook of labor economics, 4, 1043-1171.

Bertrand, M., \& Mullainathan, S. (2003). Are Emily and Greg more employable than Lakisha and Jamal? A field experiment on labor market discrimination (No. w9873). National Bureau of Economic Research.

Bound, J., Lovenheim, M. F., \& Turner, S. (2012). Increasing time to baccalaureate degree in the United States. Education Finance and Policy, 7(4), 375-424.

Cellini, S. R., \& Chaudhary, L. (2012). The labor market returns to a for-profit college education (No. w18343). National Bureau of Economic Research.

College Board. (2014). Trends in College Pricing 2013.

Deming, D. J., Goldin, C., \& Katz, L. F. (2011). The For-Profit Postsecondary School Sector: Nimble Critters or Agile Predators? (No. w17710). National Bureau of Economic Research.

Deming, D., Goldin, C., \& Katz, L. (2013). For-Profit Colleges. The Future of Children, 23(1), 137-163.

Goldin, C. D., \& Katz, L. F. (2009). The race between education and technology. Harvard University Press.

Kroft, K., Lange, F., \& Notowidigdo, M. J. (2013). Duration Dependence and Labor Market Conditions: Evidence from a Field Experiment*. The Quarterly Journal of Economics, 128(3), 1123-1167.

Lahey, J. N. (2008). Age, Women, and Hiring An Experimental Study. Journal of Human Resources, 43(1), 30-56.

Lang, K., \& Weinstein, R. (2012). Evaluating student outcomes at for-profit colleges (No. w18201). National Bureau of Economic Research.

Neumark, D. (2012). Detecting discrimination in audit and correspondence studies. Journal of Human Resources, 47(4), 1128-1157.

OECD. Education at a Glance 2013 - Indicators and Annexes.

http://www.oecd.org/edu/educationataglance2013-indicatorsandannexes.htm.

Oreopoulos, P. (2009). Why do skilled immigrants struggle in the labor market? A field experiment with six thousand resumes (No. w15036). National Bureau of Economic Research.

Pearson Foundation. (2011). Community College Student Survey.

Riach, P. A., \& Rich, J. (1987). Testing for Sexual Discrimination in the Labor Market. Australian Economic Papers, 26(49), 165-178. 
Table 1 - List of Occupations and Sample Job Titles

\section{Example Degrees for Occupation Groups}

Business, Administration and IT

$A A$ in Accounting

AA in Business Administration / Management

AA in Information Technology / Information Systems

Share of All AA Degrees by Sector

BA in Accounting / Finance

BA in Business Administration / Management

BA in Information Technology / Information Systems

Share of All BA Degrees by Sector

\section{Allied Health}

Diploma in Medical Billing and Coding

Diploma in Medical Assisting

Diploma in Licensed Practical Nursing

Diploma in Pharmacy Technician

Share of All Diplomas/Certificates by Sector

\section{Share of}

Awards in

Public Sector

(1)

0.017

0.076

0.027

0.120

0.049

0.095

0.020

0.164

0.031

0.021

0.078

0.009

0.139
Share of

Awards in

For-Profit

Sector

(2)

0.031

0.130

0.090

0.251

0.048

0.309

0.098

0.455

0.091

0.214

0.041

0.033

0.379
0.679

0.861

For-Profit

Share of All

Awards

(3)

0.324

0.305

0.456

0.100

0.186

0.273

0.296

0.731

Notes: Degree categories are based on the Classification of Instructional Programs (CIP) codes. The exact degree titles vary by institution. Certificate and Diploma data include awards of less than one year and awards of more than 1 but less than 2 years. Shares in columns 1 and 2 are calculated based on 2012 data on completions from the Integrated Postsecondary Education

Database (IPEDS). Shares are calculated within degree groups, not across them (i.e. associate's degrees in accounting as a share of all associate's degrees, not all degrees.) 
Table 2 - List of Occupations and Sample Job Titles

\section{Occupation Category}

\section{Business, Admin and IT}

Accounting / Finance

Customer Service / Sales / Marketing

Administrative / Clerical

Information Technology

\section{Allied Health}

Medical Assistant - Administrative

Medical Assistant - Clinical

Licensed Practical/Vocational Nursing

Pharmacy Technician
Payroll Manager, Billing/Collection Specialist Business Analyst, Accountant (non-CPA)

Customer Care Rep, Sales Associate

Account Executive, Product Representative

Administrative Assistant, Services Coordinator

Executive Assistant, Project Manager

IT Support / Help Desk, Training Coordinator Systems Administrator, Software Developer

Medical Biller, Medical Secretary

Medical Assistant, Clinical Support

Licensed Practical Nurse

Pharmacy Technician
Degree Required

Share of All FT Job

Vacancies

None or AA

BA

None or AA

BA

None or $A A$

BA

None or AA

BA

0.191

None or Diploma / Cert

None or Diploma / Cert

0.036

Diploma / Cert

0.012

Diploma / Cert

Notes: Occupation categories are based on the Classification of Instructional Programs (CIP) codes. Certificate and Diploma data include awards of less than one year and awards of more than 1 but less than 2 years. Sample job titles are pulled from the job search website using the occupation and keyword searches described in the text. The share of full-time job vacancies is computed by dividing the total number of vacancies posted for particular keyword search by the total number of all vacancies posted. We compute this share for three consecutive 24 hour periods and then report the average. 
Table 3 - Degrees and Certificates Awarded and Job Vacancies by Labor Market

\section{Combined Statistical Area (CSA)}

New York-Newark, NY-NJ-CT-PA

Los Angeles-Long Beach, CA

Chicago-Naperville, IL-IN-WI

Miami-Fort Lauderdale-Port St. Lucie, FL

San Jose-San Francisco-Oakland, CA

Dallas-Fort Worth, TX-OK

Phoenix-Mesa-Scottsdale, AZ

Houston-The Woodlands, TX

Boston-Worcester-Providence, MA-RI-NH-CT

Total Share

\begin{tabular}{c} 
Allied Health \\
\hline Certificates / \\
Diplomas \\
\hline
\end{tabular}

(1)

0.059

0.082

0.041

0.033

0.018

0.021

0.023

0.019

0.019

0.315
Business / Admin / IT

Associate's
Degrees $\quad$ Bachelor's Degrees

(2)

0.088

0.040

0.043

0.010

0.021

0.010

0.111

0.011

0.022

0.357
Share of All Full-Time

Job Vacancies

$\begin{array}{ccc}(3) & (4) \\ 0.064 & & 0.041 \\ 0.043 & & 0.032 \\ 0.031 & & 0.041 \\ 0.019 & & 0.019 \\ 0.017 & & 0.029 \\ 0.015 & & 0.030 \\ 0.051 & & 0.023 \\ 0.012 & & 0.025 \\ 0.037 & & 0.024 \\ \mathbf{0 . 2 8 8} & & \mathbf{0 . 2 6 4}\end{array}$

Notes: Occupation categories are based on the Classification of Instructional Programs (CIP) codes. Certificate and Diploma data include awards of less than one year and awards of more than 1 but less than 2 years. The share of full-time job vacancies is computed by summing the number of vacancies posted in the last 24 hours over 3 consecutive days, and then dividing the share of jobs in each occupation or keyword search into the total. Phoenix-Mesa-Scottsdale, AZ is based on the Core-Based Statistical Area (CBSA) definition used by the Office of Management and Budget (OMB). 
Table 4 - Experimental Design

\section{$\begin{array}{ccc}\text { Degree } & \\ \text { Occupation Category } & \text { Required } & \text { Resume Structure }\end{array}$}

1: No education, 6 years of work experience

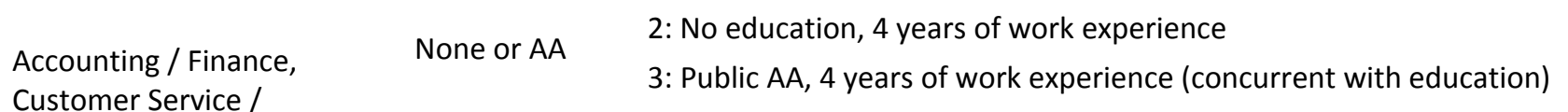

Customer Service /

4: For-profit AA, 4 years of work experience (concurrent with education)

Administrative /

Clerical, Information

1: BA, less-selective public institution, 6 years of work experience (concurrent with education)

Technology

2: $B A$, less-selective public institution, part-time experience + internships (concurrent with education)

3: $B A$, for-profit institution, 6 years of work experience (concurrent with education)

4: $B A$, for-profit institution, concurrent and part-time experience + internships (concurrent with education)

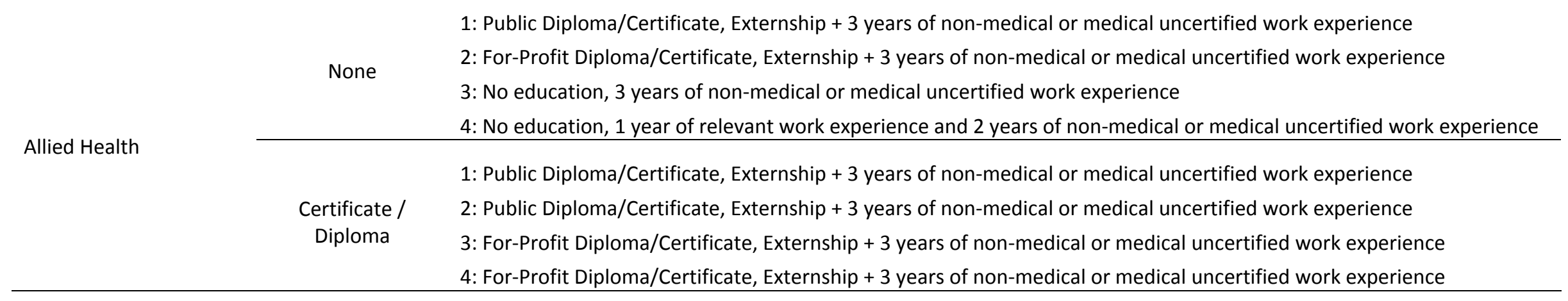


Table 5 - Power Calculations

\begin{tabular}{|c|c|c|c|c|}
\hline Treatment & & rcentage Poi & & \\
\hline Mean & Control Mean & Difference & Alpha & Sample Size (Jobs) \\
\hline 0.065 & 0.075 & 0.010 & 0.10 & 4,024 \\
\hline 0.055 & 0.045 & 0.010 & 0.05 & 3,728 \\
\hline 0.055 & 0.045 & 0.010 & 0.10 & 2,936 \\
\hline 0.0875 & 0.0725 & 0.015 & 0.05 & 2,567 \\
\hline 0.0575 & 0.0425 & 0.015 & 0.05 & 1,656 \\
\hline 0.0575 & 0.0425 & 0.015 & 0.1 & 1,305 \\
\hline 0.060 & 0.040 & 0.020 & 0.05 & 931 \\
\hline
\end{tabular}

Notes: All calculations assume a beta (power) level of 0 .8. Alpha is the significance level. The sample size refers to jobs, and we send four resumes to each job vacancy. See Table 4 for details. 
Table 6 - Pilot Study Results

$\begin{array}{lcccc} & (1) & (2) & (3) & (4) \\ \text { For-Profit } & 0.001 & -0.002 & 0.001 & 0.006 \\ & {[0.039]} & {[0.045]} & {[0.039]} & {[0.045]} \\ \text { Community College } & 0.031 & 0.032 & 0.031 & 0.037 \\ & {[0.044]} & {[0.055]} & {[0.044]} & {[0.052]} \\ \text { FP * Degree Required } & & & 0.050 & 0.000 \\ & & & {[0.063]} & {[0.065]} \\ \text { CC * Degree Required } & & & 0.020 & 0.022 \\ & & & {[0.066]} & {[0.075]} \\ \text { Sample is jobs where } & \mathrm{X} & \mathrm{X} & & \\ \text { degree not required } & & \mathrm{X} & & \\ \text { Work history fixed effects } & & \mathrm{X} & \mathrm{X} \\ \text { Sample Size } & 210 & 210 & 278 & 278\end{array}$

